ARTICLE

Received 31 Jan 2013 | Accepted 9 Jul 2013 | Published 5 Aug 2013 DOl: 10.1038/ncomms3269

\title{
Conventional tree height-diameter relationships significantly overestimate aboveground carbon stocks in the Central Congo Basin
}

Elizabeth Kearsley 1,2,3, Thales de Haulleville ${ }^{3,4}$, Koen Hufkens ${ }^{2}$, Alidé Kidimbu ${ }^{5,6}$, Benjamin Toirambe ${ }^{3}$, Geert Baert ${ }^{7}$, Dries Huygens ${ }^{2,8,9}$, Yodit Kebede ${ }^{10,11}$, Pierre Defourny ${ }^{10}$, Jan Bogaert ${ }^{4}$, Hans Beeckman $^{3}$, Kathy Steppe ${ }^{1}$, Pascal Boeckx ${ }^{2} \&$ Hans Verbeeck ${ }^{1}$

Policies to reduce emissions from deforestation and forest degradation largely depend on accurate estimates of tropical forest carbon stocks. Here we present the first field-based carbon stock data for the Central Congo Basin in Yangambi, Democratic Republic of Congo. We find an average aboveground carbon stock of $162 \pm 20 \mathrm{MgCha}^{-1}$ for intact old-growth forest, which is significantly lower than stocks recorded in the outer regions of the Congo Basin. The best available tree height-diameter relationships derived for Central Africa do not render accurate canopy height estimates for our study area. Aboveground carbon stocks would be overestimated by $24 \%$ if these inaccurate relationships were used. The studied forests have a lower stature compared with forests in the outer regions of the basin, which confirms remotely sensed patterns. Additionally, we find an average soil carbon stock of $111 \pm 24 \mathrm{MgCha}^{-1}$, slightly influenced by the current land-use change.

\footnotetext{
${ }^{1}$ Laboratory of Plant Ecology, Department of Applied Ecology and Environmental Biology, Faculty of Bioscience Engineering, Ghent University, Ghent 9000 , Belgium. ${ }^{2}$ Isotope Bioscience Laboratory-ISOFYS, Department of Applied Analytical and Physical Chemistry, Faculty of Bioscience Engineering, Ghent University, Ghent 9000, Belgium. ${ }^{3}$ Laboratory for Wood Biology and Xylarium, Royal Museum for Central Africa, Tervuren 3080, Belgium. ${ }^{4}$ Biodiversity and Landscape Unit, Gembloux Agro-Bio Tech, University of Liège, Gembloux 5030, Belgium. ${ }^{5}$ Département d'Ecologie et Gestion des Ressources Végétales, Faculté des Sciences, Université de Kisangani, BP 2012 Kisangani, Democratic Republic of Congo. ${ }^{6}$ Herbarium National, INERA, BP 28 Yangambi, Democratic Republic of Congo. ${ }^{7}$ Department of Plant Production, University College Ghent, Ghent 9000, Belgium. ${ }^{8}$ Institute of Agricultural Engineering and Soil Science, Faculty of Agricultural Sciences, Universidad Austral de Chile, Valdivia 5090000, Chile. ${ }^{9}$ Instituto Multidisciplinario de Biología Vegetal - IMBIV, Consejo Nacional de Investigaciones Científicas y Técnicas de Argentina, Facultad de Ciencias Exactas, Físicas y Naturales, Universidad Nacional de Córdoba, Córdoba 5000, Argentina. ${ }^{10}$ Earth and Life Institute, Université catholique de Louvain, Louvain-la-Neuve 1348, Belgium. ${ }^{11}$ Wageningen University and Research Centre, Farming Systems Ecology Group, 6708 PG Wageningen, The Netherlands. Correspondence and requests for materials should be addressed to E.K. (email: elizabeth.kearsley@ugent.be).
} 
$\mathrm{T}$ ropical forests represent a crucial carbon pool as they, reportedly, store $40-50 \%$ of all terrestrial carbon ${ }^{1,2}$ and influence the global carbon balance when changes are induced due to climate change ${ }^{3}$ and anthropogenic disturbances. In order to understand and quantify tropical forest carbon uptake and losses, accurate carbon stock reference data are needed ${ }^{4}$, as well as estimates of carbon fluxes resulting from both natural processes and land-use changes ${ }^{1,5}$. The accuracy of these reference data is essential for the implementation of climate mitigation policies to reduce emissions resulting from deforestation and forest degradation (REDD, UN Framework Convention on Climate Change, www.un-redd.org) ${ }^{6,7}$. Currently, the uncertainty associated with these data is high and there are still large gaps in our knowledge with respect to the actual amount of carbon stored in tropical forests and the stability of this pool ${ }^{4}$.

In African tropical forests, in particular, there are major challenges with respect to estimating carbon stocks and fluxes. Saatchi et al. ${ }^{8}$ developed a benchmark map of carbon stocks across the tropics, predicting a gradient in Central Africa with highest stocks in western and eastern parts of the Congo Basin. This gradient is not always predicted ${ }^{9}$, and more data is needed for effective mapping, which is dependent on spatially extensive ground-based measurements to reduce regional uncertainties. To date, African tropical forests have been underrepresented in carbon research mainly due to a lack of resources for scientific research, limited logistical support, poor infrastructure and periodic political instability ${ }^{9,10}$. Only a limited number of inventoried and permanent monitoring plots have been established given the considerable extent of the African tropical forest ${ }^{11}$. The few available inventoried plots are unevenly distributed, with a high concentration in the outer regions of the Congo Basin, leaving the centre of the basin unexplored ${ }^{10,11}$. Biomass estimates for these plots have been extrapolated to the entire African tropical forest based on pan-tropical allometric equations ${ }^{12,13}$. These equations are generally parameterized without data from the African continent due to the lack thereof $^{13}$. Only the study by Feldpausch et al. ${ }^{14}$ has recently expanded the frequently used pan-tropical Chave et al..$^{13}$ equation with African data from the western Congo Basin. The robustness and accuracy of this equation has been noted for some African regions ${ }^{15,16}$, with its strength lying in the large sample size of tropical trees compared with the other equations. Nevertheless, the use of pan-tropical equations ${ }^{12,13}$ in unstudied areas needs to be done with care as it could produce systematic errors in carbon stock estimates, specifically if not all variables, namely diameter, wood density and tree height, are accounted for.

Here we report the first inventory-based carbon data obtained from a central location in the Congo Basin, situated in the UNESCO Man and Biosphere (MAB) reserve at Yangambi (YGB), Democratic Republic of Congo (DRC) (Fig. 1), with estimates for both aboveground live tree and soil carbon stocks. Thirteen 1-ha plots are established in intact old-growth forest, including two forest types namely, mixed semideciduous $(n=8)$ and riparian mono-dominant evergreen Gilbertiodendron dewevrei $(n=5)$ forests. In the mixed forests, the species Scorodophloeus zenkeri, Panda oleosa, Anonidium mannii, Petersianthus macrocarpus, Staudtia kamerunensis and Erythrophleum suaveolens are abundant. In addition, to assess the effect of deforestation and regrowth at local scales, seven plots of $1 \mathrm{ha}$ are established in previously deforested areas of mixed semideciduous forests, with varying regrowth ages after slash-and-burn agriculture, namely fallow ( $n=3)$ next to young $(n=3)$ and old $(n=1)$ regrowth forest. Soil carbon stocks to a depth of $100 \mathrm{~cm}$ are quantified for all forest types except for the old regrowth forest. A comparison of aboveground carbon stocks in old-growth forests is made with AfriTRON sites ${ }^{11}$ in western and eastern Congo Basin, in order to assess whether our first ground-based observations for this important region confirm the spatial trends observed by remote sensing ${ }^{8,9}$ and to quantify possible intrinsic differences in carbon stocks.

\section{Results}

YGB aboveground carbon stocks are lower. With an aboveground carbon stock in live free-standing woody stems (minimum diameter $10 \mathrm{~cm}$ ) in old-growth forest at YGB of $162 \pm 20 \mathrm{MgCha}^{-1}$, our estimates are $19 \%$ lower and significantly different $(P<0.001, \mathrm{Df}=2)$ from estimates at the AfriTRON sites ${ }^{11}$ (Fig. 2) in the Congo Basin. Lewis et al. ${ }^{11}$ report an average of $202 \mathrm{MgCha}^{-1}$ for African tropical forest, and an even higher average in the Congo Basin, with

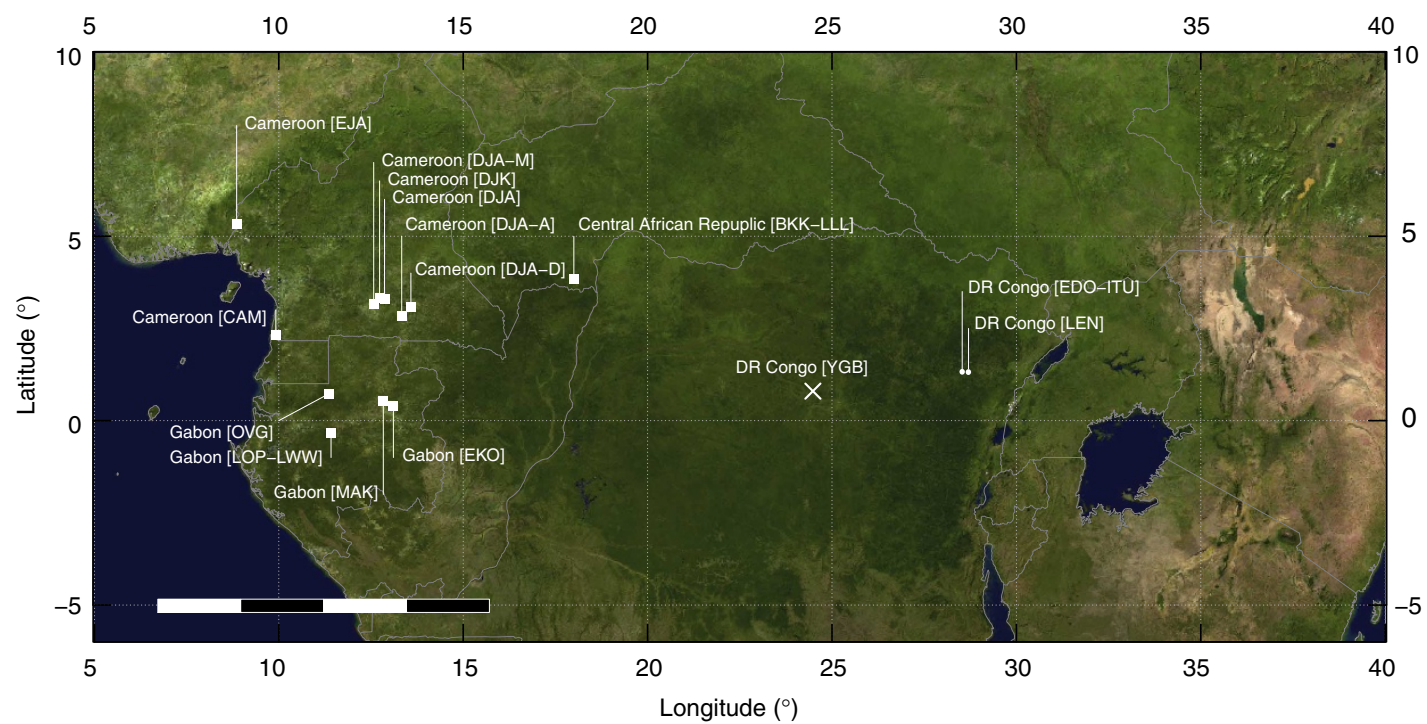

Figure 1 | Site locations. MODIS composite (NASA, Blue Marble) with the YGB study site and AfriTRON sites superimposed ${ }^{11}$. The sites are separated into different regions: squares indicate western Congo Basin sites, circles indicate eastern Congo Basin sites, and the cross indicates the Central Congo Basin site in YGB. In the scale bar, one block equals $250 \mathrm{~km}$. 


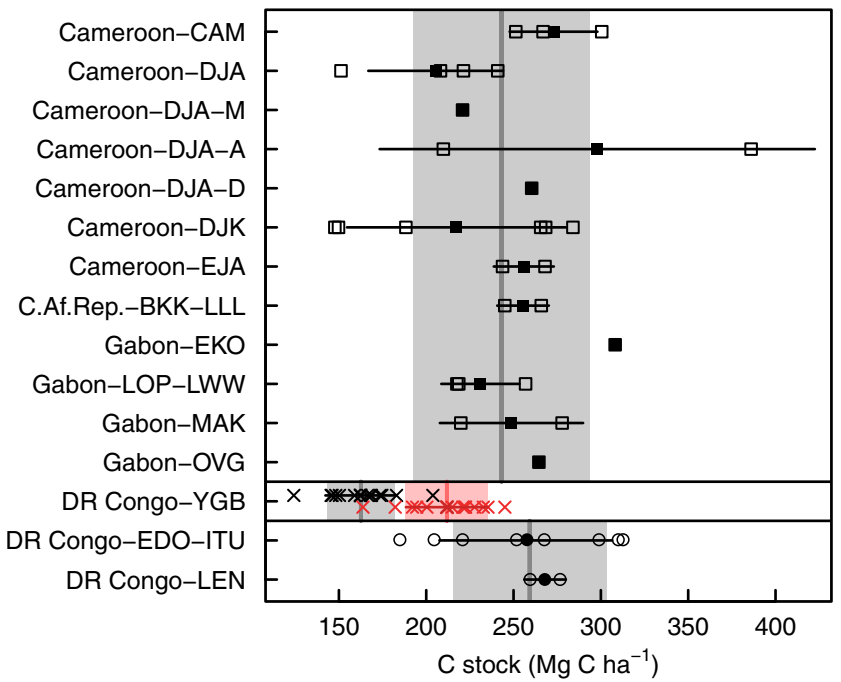

Figure 2 | Comparison between aboveground carbon stock at YGB and sites from the AfriTRON network. Sites from the AfriTRON network ${ }^{11}$ are grouped according to location, West Congo Basin (squares) and East Congo Basin (circles), respectively. All acronyms refer to the applied site names in the AfriTRON network. Aboveground carbon stocks at YGB are incorporated as a separate region, Central Congo Basin (crosses). All carbon stocks are based on the same allometric equation for biomass ${ }^{13}$. For the YGB site, a distinction is made between carbon stocks estimated using a site-specific height-diameter relationship (grey line indicates mean) and a height-diameter relationship proposed for Central Congo Basin ${ }^{14}$ (red line indicates mean). The overall mean carbon stocks for the separate regionsWest Congo Basin, Central Congo Basin and East Congo Basin-are indicated by a grey line. The grey and red boxes indicate s.d. values along the mean. The significantly lower carbon stocks at YGB are emphasized, and the possible overestimation using the generalized height-diameter relationship for Central Congo Basin by Feldpausch et al. ${ }^{14}$ is indicated in red. Within each region, a detailed representation of the same data grouped into clusters with plot locations close together ${ }^{11}$ is shown indicating the large heterogeneity associated with carbon stock estimates, with all individual plot estimates (open symbols) and the mean of the cluster (filled symbols) including s.d.

$243 \mathrm{MgCha}^{-1}$ for the western Congo Basin and $259 \mathrm{MgCha}^{-1}$ for eastern Congo Basin sites (Figs 1 and 2). Although the AfriTRON data show a large degree of variability within each geographic region, most AfriTRON sites have a significantly higher carbon stock than those estimated for YGB (Fig. 2). The lower aboveground carbon stock at YGB is very remarkable and can be attributed to a different forest structure, where trees do not reach the same height for a given tree diameter as in the western or eastern Congo Basin (Fig. 3). When comparing tree heightdiameter regression curves developed for Central Africa ${ }^{11,14,17}$ with those based on the YGB dataset, we found an asymptotic height difference of $9.4 \pm 0.9 \mathrm{~m}$ (Fig. 3, Table 1) resulting in an overestimation in aboveground carbon stocks of $12-25 \%$ (median $24 \%$ ) equivalent to $29-62 \mathrm{MgCha}^{-1}$ (median $53 \mathrm{MgCha}^{-1}$ ). This results in an overestimated mean carbon stock of $212 \pm 24 \mathrm{MgCha}^{-1}$ (Fig. 2, red points). This is a first indication that height-diameter allometry in some regions in Central Africa can differ from general regressions for Central Africa $^{14,17}$, and that more localized height-diameter allometry is required.

Tree height is the determining structural factor. To explore in more detail the forest structural parameter responsible for the observed lower aboveground carbon stocks, we compared our data in more detail with datasets from sites in the Dja Faunal Reserve in Cameroon in the west of the Congo Basin and in the Ituri Dynamics Plots in the east, with a distinction of mixed and mono-dominant $G$. dewevrei forest types (Table 2). For these areas, carbon stocks, basal area, stem density and wood density were available from literature, but explicit height data are lacking. In addition, data on soil and climate are available. By comparing mixed and mono-dominant plots separately, we were able to get a better view on the structural parameters driving the biomass differences.

For mixed forests in these three sites, aboveground carbon stocks do not follow the same spatial gradient as generally seen for the Congo Basin ${ }^{8}$, with the Dja mixed forests showing smaller stocks, similar to the YGB ones. In the Dja reserve, a lower $(P<0.03)$ basal area is found, whereas both stem density and wood density are not significantly different from that in the YGB mixed forest $(P=1)$. The combination of a lower basal area with the same amount of trees in the plots in Dja, indicates that the average tree diameter is lower than that in YGB. In order to reach a similar carbon stock as in YGB, for a specific diameter, trees need to grow taller. This shows that differences in heightdiameter relationships are a driver for the amount of carbon stored in these sites.

Mixed forests in Ituri represent a significantly $(P=0.01)$ larger carbon stock than in YGB. Comparison of the structural parameters shows that a higher mean wood density $(P<0.001)$ is found in Ituri than in YGB with other variables (Table 2) statistically indistinguishable $(P>0.6)$. This shows that the species composition is an important factor determining the larger carbon stock in Ituri, with a tendency for species with a higher wood density. This does not preclude that additional differences in height-diameter relationships could be present. In the mixed forests of these two regions, both basal area and stem density are similar. This indicates that the average tree diameter in both regions is similar and that a different maximal tree height attained in these forests could be the driver for the difference in carbon stock.

By considering the mono-dominant $G$. dewevrei forests for the three regions, we exclude the influence of species composition on carbon stock. A significantly lower $(P<0.001)$ carbon stock is found in YGB, whereas all other forest stand variables are similar (Table 2). The basal area in YGB is slightly lower $(P=0.04)$ than in Ituri, but similar to the values in Dja. With stem density being not significantly different for all regions, this indicates that monodominant forests in YGB do not have a lack of trees with a large diameter compared with the other regions. Mean wood density is slightly lower in YGB, although not significantly $(P=0.1)$. Consequently, the remaining determinative variable for the estimation of carbon stock is the total tree height reached in these mono-dominant forests, which clearly confirms our overall conclusion that tree height is largely explaining the significantly lower stock in YGB.

Land-use change effect on above- and belowground carbon stock. We estimated that aboveground carbon stocks in live trees with a minimum diameter of $10 \mathrm{~cm}$ in intact old-growth forest average $162 \pm 20 \mathrm{MgCha}^{-1}$, with no significant differences between the different old-growth forest types examined (Fig. 4). For previously deforested plots, a lower aboveground carbon stock is found, varying according to land-use type and the age of any regenerated forest patch, with higher values for older plots with forest regrowth. There is, however, no corresponding difference in soil carbon stocks between intact and degraded forest plots. Soil carbon stocks to a depth of $100 \mathrm{~cm}$ in intact forest 

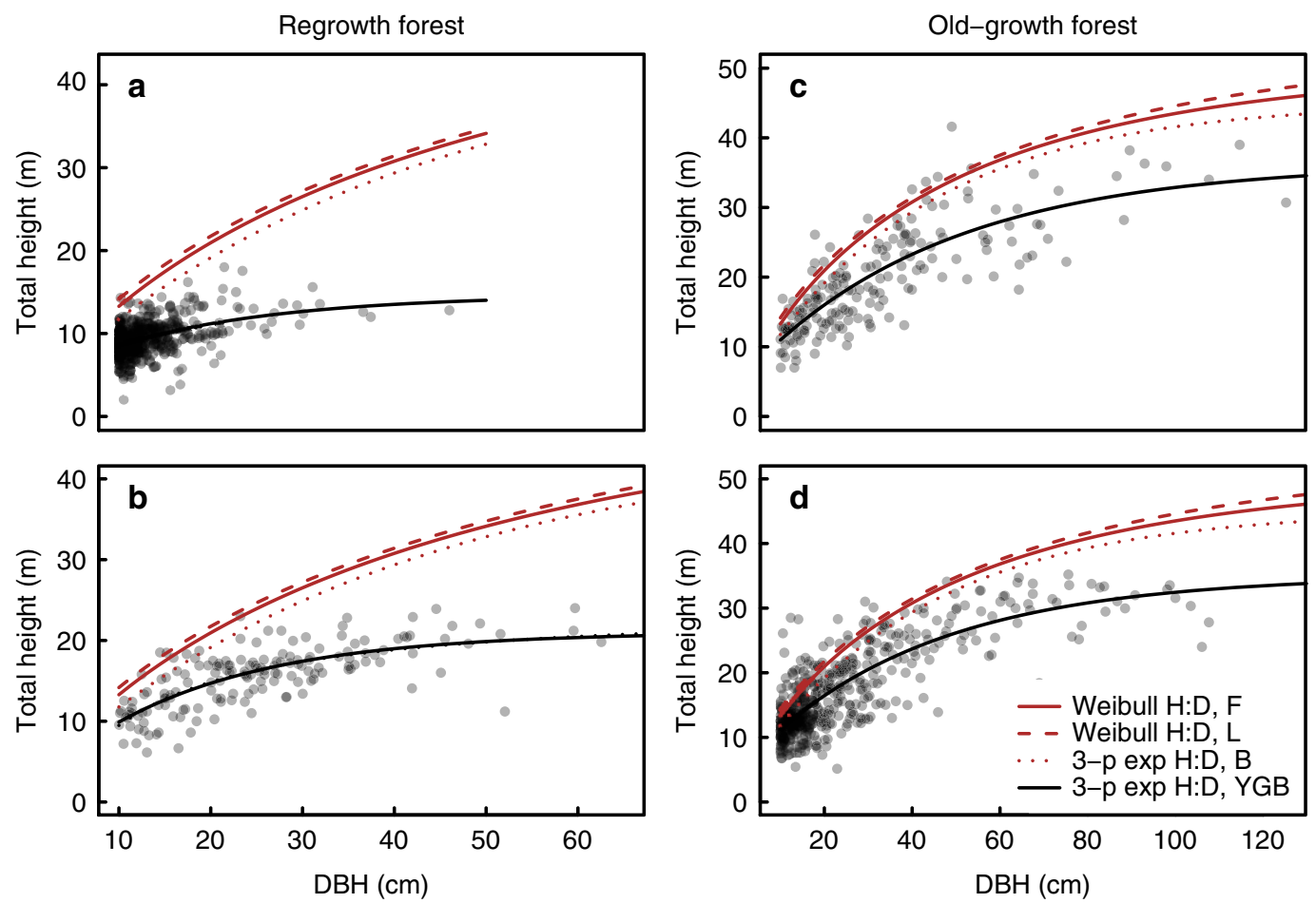

Figure 3 | Height-diameter models for different inventoried forest types at the YGB reserve in the Central Congo Basin. Comparison is made between regrowth and old-growth forests using different scales. (a) Fallow; (b) Young regrowth forest; (c) mixed old-growth forest; (d) mono-dominant old-growth forest. In black: the three-parameter exponential height-diameter (H:D) model optimized for the YGB site. In red: regional models for Central Africa. Weibull H:D, F, Feldpausch et al. ${ }^{14}$ model; Weibull H:D, L, model used by Lewis et al. ${ }^{11}$ (dashed); 3-p exp H:D, B, Banin et al. ${ }^{17}$ model (dotted). The use of regional models results in an overestimate of tree heights and the biomass estimates are thus affected.

Table 1 | Coefficients for height-diameter relationship in a three-parameter exponential regression model.

\begin{tabular}{llllcc} 
Forest type & \multicolumn{1}{c}{$\boldsymbol{a}$} & $\boldsymbol{b}$ & $\boldsymbol{c}$ & AIC & RSE \\
\hline Mixed & 36.3576 & 31.6591 & 0.0221 & $1,085.653$ & 4.221 \\
Mono-dominant & 35.0437 & 30.4327 & 0.0246 & $2,552.917$ & 4.053 \\
Young regrowth & 21.0279 & 19.5718 & 0.0564 & 786.6445 & 2.585 \\
Fallow & 14.6846 & 10.4496 & 0.0547 & $1,952.425$ & 1.824 \\
Africa & 45.1 & 42.8 & 0.025 & & 452 \\
\end{tabular}

AIC, Akaike information criterion; $n$, number of trees; RSE, standard residual error. Regression model: $\left(H=(a-b) \times e^{-c D}\right) . a, b$ and $c$ are the optimized parameters for the individual equations per forest type, which represent, respectively, the maximum asymptotic height, the difference between minimum and maximum height, and shape of the curve ${ }^{17}$.

averaged $111 \pm 24 \mathrm{MgCha}^{-1}$ and was equivalent to $68 \%$ of the aboveground stock. A significantly higher stock is found in mono-dominant forests with an average of $128 \pm 27 \mathrm{MgCha}^{-1}$, compared with $95 \pm 11 \mathrm{Mg} \mathrm{Cha}^{-1}$ in mixed forests (Fig. 4). Even after forest clearing of mixed forest sites, the soil carbon stock remains high, although a gentle gradient is observable. Soil carbon stocks in fallow plots average $74 \pm 8 \mathrm{MgCha}^{-1}$ and increase significantly with regrowth age as young regrowth forest shows an average of $101 \pm 22 \mathrm{MgCha}^{-1}$ and thus return to the amount of soil carbon stock of the mixed forest from which they originate (Supplementary Table S1).

\section{Discussion}

Our observations, of lower aboveground carbon stocks for the Central Congo Basin, confirm patterns found by remote sensing ${ }^{8}$, indicating that the Western Congo Basin in Gabon and Southern Cameroon, and Eastern DRC support higher carbon stocks. We attribute this low stock mainly to a difference in diameter-height relationships.

The lower carbon stocks and reduced canopy height at YGB could be related to climate and soil properties, the local available species pool or past natural and anthropogenic disturbances $8,18-21$. Disturbances due to past selective logging can have a substantial impact on forest structure ${ }^{22}$ and, therefore, on carbon stocks. Nevertheless, based on our own field observations, analysis of the species composition (Supplementary Fig. S1), communication with local foresters and an assessment of historical archives of the YGB station, we found no single indication that selective logging activities have been conducted in the study area in the last 150 years. Disturbance due to edge effects $^{23,24}$ could be a factor for some plots close to the edge (Supplementary Fig. S2), but this effect remains negligible as we did not observe a significant difference between these plots and the plots at a longer distance from the edge. Relatively high average air temperatures in this lowland study area could explain 
Table 2 | Aboveground carbon stock in relation to structural and climate parameters for study sites.

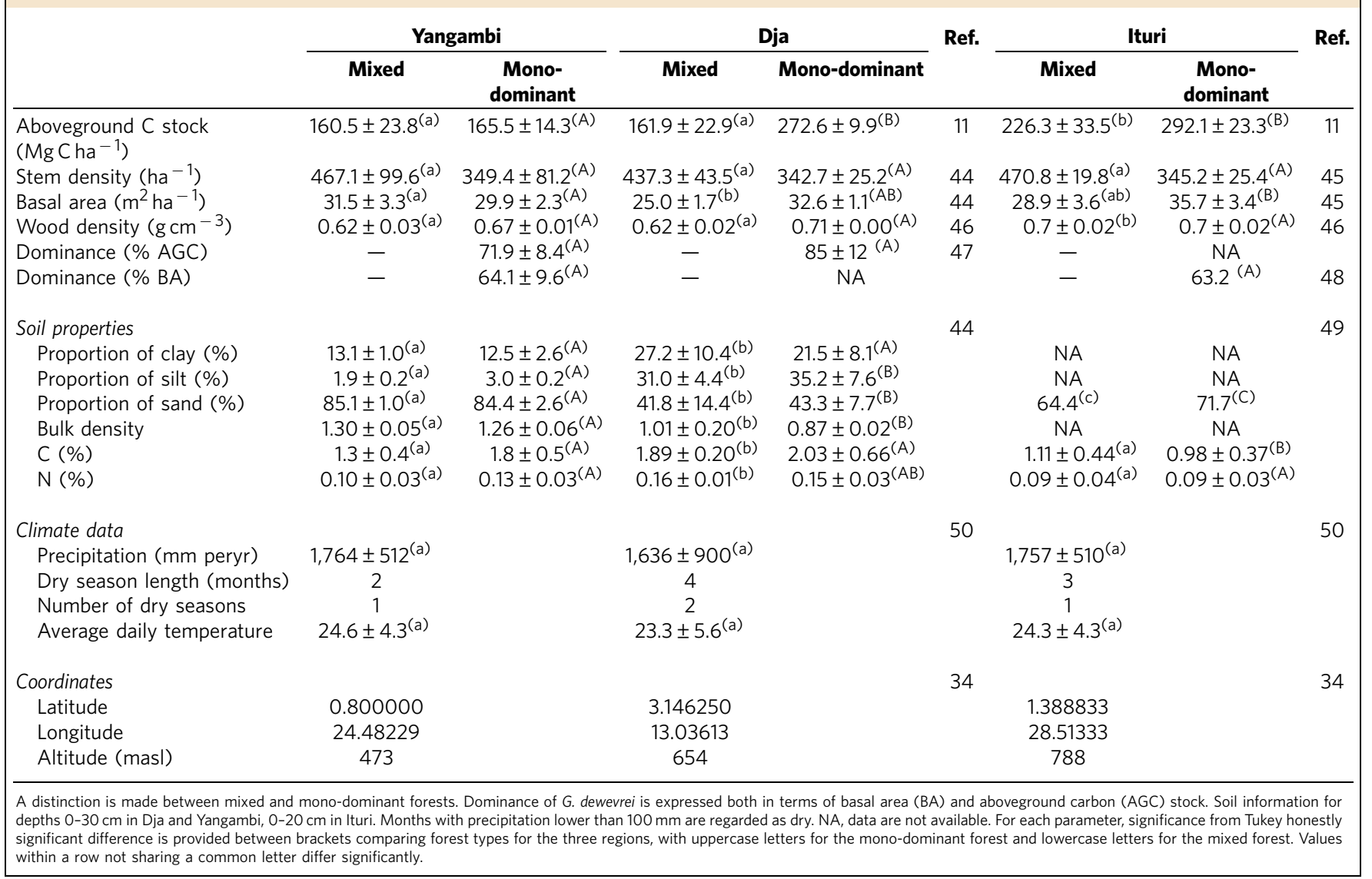

the lower standing biomass because it may cause increased turnover rates and photosynthetic inhibition ${ }^{25}$. This could be an important factor, but in itself cannot explain the significantly lower carbon stock in YGB as the mean annual temperatures in Ituri and Dja are similar to that in YGB. The effect of soil conditions is probably more important here. Soils in our study area are sandier compared to those in Dja and Ituri (Table 2), with sandy soils generally characterized by lower fertility and more limited water retention. The low $\mathrm{N}$ content and the high sand fraction in YGB indicate resource-poor soils, both in terms of nutrients and water availability. This low $\mathrm{N}$ content is also found in Dja and Ituri, but the sand fraction in these soils is lower providing a higher water holding capacity, specifically in Dja. Additionally, the higher bulk density for the more sandy soils in YGB indicates more compaction, which influences root penetration and reduces water infiltration. These soil properties can have an effect on height-diameter relationships ${ }^{26}$ through nutrient limitations or a reduced water holding capacity, both of which influence the amount of carbon stored in biomass. In addition, there may be issues with mechanical instability in sandy soils $^{21}$, increasing natural disturbances and leading to a lower standing biomass, or favouring smaller trees. This soil effect could be a driver for the differences in carbon stocks between YGB and $\mathrm{Dja}$, with height-diameter relationships being the main structural difference between these sites, both for mixed and mono-dominant forests. A lower maximal tree height is reached on resource-poor and less stable soils in YGB. Also in the mono-dominant forests of Ituri, tree height is a major factor driving the higher biomass, but the comparison with mixed forests in Ituri highlights wood density as an additional factor. In these forests, a higher mean wood density is found compared with the YGB sites, with the Ituri sites on less sandy soils. In the study by Gourlet-Fleury et al. ${ }^{5}$ the contrary was shown, with higher carbon stocks in less fertile regions due to a tendency to support slow-growing species with a higher wood density and possibly due to a slower turnover rate ${ }^{27}$. Nevertheless, we show that when eliminating differences in the species pool, via the analysis of mono-dominant forests, a lower aboveground carbon stock on less fertile soils of YGB is explained through a lower maximal tree height.

To date, no clear general relationship has been established between forest carbon stocks and soil properties, and the available results are contradictory $5,18,21,28$. If soil texture or other soil properties are indeed related to forest structure, applying equations developed from trees on a different soil type could give rise to highly inaccurate carbon stock estimates across the Congo Basin. Regressions based on large subcontinental regions that are used ${ }^{14,17}$, may need to be replaced with a regional approach or an approach based on climatic or soil classifications.

However, the spatial distributions of soil type, forest structure and carbon stocks in tropical Africa are poorly known $^{8,29}$ and quantification of the carbon emission and storage potential of these forests remains challenging. At local scales, emissions resulting from deforestation, degradation and regrowth can be determined by measuring forests at different stages of degradation ${ }^{6}$. Looking at different regrowth stages in our study area, we made two main observations. First, within the first few decades of regrowth, the aboveground carbon stock did not return to its initial state. This trend could persist, as tree species composition has changed and there is a tendency towards species with a lower wood density (Supplementary Table S2), hence 


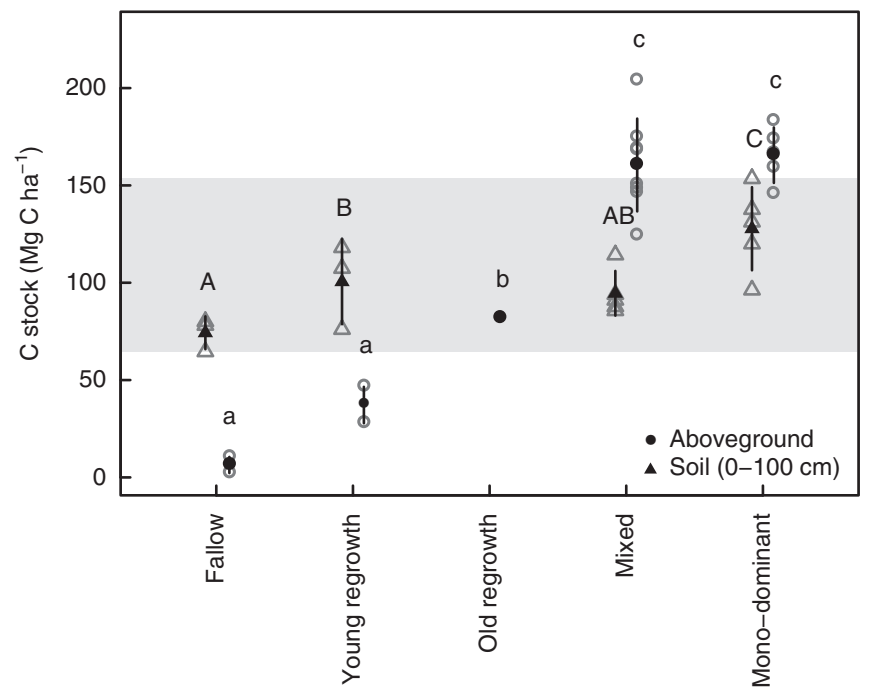

Figure 4 | Aboveground and soil carbon stock per forest type for inventory plots in the YGB reserve. Forest types are arranged from degraded to old-growth forest and show the impact of deforestation on aboveground carbon stock (circles) and soil carbon stock (triangles). The grey box indicates the variability range for soil carbon stocks. Significance from Fisher's least significance difference test is visualized, with uppercase letters for the soil carbon stock and lowercase letters for the aboveground carbon stock. Values not sharing a common letter differ significantly.

decreasing the total carbon stock of this type of disturbed forest. Secondly, soil carbon stocks remain high even after degradation of the forest (Fig. 4), but do show sensitivity to land-use change. An initial nonsignificant soil carbon decline is observed due to forest clearing for agricultural use. However, the stock rapidly increases to a significantly higher level after two decades of regrowth. Because of the large amount of carbon stored in the soil it will be crucial to quantify the impact of possible future agricultural intensification, as land use after deforestation has significant potential effects on soil carbon ${ }^{30-32}$. If future demand for agricultural crops exceeds the yield of the traditional agricultural activities, agricultural intensification will become a necessity. This intensification could eventually require less land than currently to sustain the local population ${ }^{33,34}$, thereby securing the remaining forest and its carbon stock. However, the choice of agricultural system will critically affect the carbon balance. Land management can, depending on the disturbance intensity, drastically change the amount of carbon stored in the soil, with tillage and fertilization affecting soil disturbance and carbon decomposition rates ${ }^{30}$. The local integrated carbon balance of different agricultural systems therefore needs to be considered.

In the context of climate change mitigation policies (for example, REDD) for tropical Africa, major challenges remain. Our results show that height-diameter regressions developed from data obtained from forest sites in the outer regions of the Congo Basin do not produce accurate aboveground carbon stock estimates for central areas of the basin. The current best carbon stock estimate for structurally intact closed canopy African tropical forest ${ }^{11}$ of $202 \mathrm{MgCha}^{-1}$ is, therefore, probably an overestimate. There are significant consequences of the $24 \%$ overestimation of aboveground carbon stocks in YGB. With annual net deforestation and degradation rates in the Congo Basin estimated to be $0.17 \%$ and $0.09 \%$, respectively, between 2000 and 2005 (ref. 35), this biased carbon stock estimate could result in an overestimation of carbon loss. Nevertheless, confirmation of our results is needed through the establishment of inventory plots throughout the basin covering a larger area. Allometric equations developed specifically for Central Africa and pan-tropical models need to be validated and updated to improve the quality of regional and national carbon stock inventories. In addition, the spatial distribution, variability and response to future climate of soil carbon stocks are practically unknown ${ }^{29,31}$. We conclude that a spatially explicit understanding of both the aboveground carbon and the soil carbon stock remains crucial in developing an overall carbon budget for tropical African forests in order to support current and future climate policy measures.

\begin{abstract}
Methods
Study area. This study was carried out in the UNESCO Man and Biosphere reserve in YGB, $\sim 100 \mathrm{~km}$ west of Kisangani, DRC. The reserve covers an area of $6,297 \mathrm{~km}^{2}$ (ref. 36), just north of the Congo River, and all study sites are located in the south-western $\left(\mathrm{N}_{00}^{\circ} 47^{\prime}\right.$; E2 $\left.4^{\circ} 30^{\prime}\right)$ and north-western part (N00 $59^{\prime}$; E24 $\left.{ }^{\circ} 32^{\prime}\right)$ of the reserve. The region has an Af-type tropical rainforest climate ${ }^{37}$ (following Köppen-Geiger). The site receives upto $1,762 \pm 295 \mathrm{~mm}$ per year (1961-2010) of rain and has one dry season from January to February with monthly precipitation lower than $100 \mathrm{~mm}$ (ref. 50). Temperatures are high and constant throughout the year with a minimum of $24.2 \pm 0.4^{\circ} \mathrm{C}$ in July and a maximum of $25.5 \pm 0.6^{\circ} \mathrm{C}$ in March. Soils in the YGB plateau are ferralsols primarily formed from aeolian sediments, composed mostly of quartz sand, kaolinite clay and hydrated iron oxides $^{38,39}$. Vegetation in the reserve is characterized by moist semideciduous rainforest, with fragments of moist evergreen rainforest, transition forest, agricultural land, fallow land and swamp forest ${ }^{38}$.
\end{abstract}

Plot selection and inventory. A preliminary classification of the study area was made using SPOT-4 HRVIR, Landsat and geo-eye satellite images ${ }^{40}$ using an object based classification approach. Plot locations were assigned within each classification type before fieldwork. The forest type was validated in the field and permanent inventory plots of 1 ha have been installed ${ }^{41,42}$. Topography of the region is gentle, and squared or rectangular plots were realized on the ground (no projected area). A standardized international inventory protocol for tropical forest was used ${ }^{42}$ (RAINFOR) to assure comparability with other studies. All live stems with a diameter larger than $10 \mathrm{~cm}$ were tagged, measured for diameter at breast height at $1.3 \mathrm{~m}$ and identified upto species level. Buttressed trees, although a rarity in the region, and stilt-rooted trees are measured $50 \mathrm{~cm}$ above the highest root, where the trunk shape is cylindrical. When a deformity is present at breast height, the diameter is measured $2 \mathrm{~cm}$ lower. Species identification was done with the help of local botanists of the Institut National pour l'Etude et la Recherche Agronomiques.

Height measurements. All tree individuals were classified in the field into diameter classes (that is, $10-20,20-30,30-50,>50 \mathrm{~cm}$ ) and all species contributing to $95 \%$ of the basal area of the plot were selected for further measurement. For each of these species, two individuals were selected within each diameter class. These individuals were measured for tree height using a Nikon Laser Rangefinder Forestry Pro hypsometer. The top of the tree is determined from different view angles and multiple measurements are made to account for over- or underestimation. When the top of an individual is not visible, a different individual using the same selection criteria is selected.

Wood density measurements. The same individuals selected for tree height measurements are selected for wood sampling to determine species wood density, defined as the ratio of oven dry weight and fresh volume. Wood samples with an average size of $5 \times 5 \times 5 \mathrm{~cm}^{3}$ are taken under the bark. For those species with no wood density data, a genus-average was taken or when genus data was unavailable, a family-average was used. For a few remaining species from which the family did not occur elsewhere in the plot and for the remaining unidentified individuals, a site-average was used. Mean wood density for each plot was weighted by basal area.

Height-diameter regressions. Stand-specific height-diameter regression models were developed for each forest type. All trees known to be broken, damaged or leaning more than $10 \%$ were excluded from the analysis. Weibull, ChapmanRichards, logistic, power and two- and three-parameter exponential models were compared. The optimal model was selected based on the Akaike Information Criterion and the residual standard error, and was further used to determine tree heights for aboveground carbon stock estimation. No tree height measurements are available for old regrowth forest $(n=1)$, and the model for mixed semideciduous forest was used as similar species were present.

Allometric equations. The relation of Chave et al. ${ }^{13}$ for moist tropical forest including height and wood density was selected for aboveground carbon stock estimation, with biomass assumed to be $50 \%$ carbon. 
Soil carbon storage. Soil cores were collected using five depth increments: 0-10, $10-20,20-30,30-50$ and $50-100 \mathrm{~cm}$. From each replicated plot per forest type a composite soil sample $(n=10)$ was prepared per depth. Composite samples were oven-dried at $50^{\circ} \mathrm{C}$. Carbon content was determined via element analyses using continuous flow EA-IRMS. For each depth increment, carbon stocks $\left(\mathrm{MgCha}^{-1}\right)$ were determined as a product of bulk density $\left(\mathrm{g} \mathrm{cm}^{-3}\right)$, carbon concentration (\%) and thickness of the increment layer $(\mathrm{cm})$. Soil texture was determined by means of the percentage of sand, silt and clay. Analyses were performed on air-dried soil fractions $(<2 \mathrm{~mm})$. The sand fraction $(>63 \mu \mathrm{m})$ was separated by wet sieving; the silt and clay fractions were determined by the pipette method of Köhn after dispersion with sodium hexametaphosphate ${ }^{43}$.

Statistics. One-way analysis of variance is used followed by a Tukey honestly significant difference test to compare the means of the AfriTRON sites ${ }^{11}$ and the YGB sites. To compare the carbon stocks of the different forest types in YGB, Fisher's least significance difference test is used.

\section{References}

1. IPCC Climate Change 2007: Mitigation of Climate Change. (eds Metz, B., Davidson, O., Bosch, P., Dave, R. \& Meyer, L.) (Cambridge University Press, 2007).

2. Lewis, S. L. Tropical forests and the changing earth system. Phil. Trans. R. Soc. Lond. B 361, 195-210 (2006).

3. Pan, Y. et al. A large and persistent carbon sink in the world's forests. Science 333, 988-993 (2011).

4. Huntingford, C. et al. Simulated resilience of tropical rainforests to $\mathrm{CO} 2-$ induced climate change. Nat. Geosci. 6, 1-6 (2013).

5. Gourlet-Fleury, S. et al. Environmental filtering of dense-wooded species controls above-ground biomass stored in African moist forests. J. Ecol. 99, 981-990 (2011).

6. Gibbs, H. K., Brown, S., Niles, J. O. \& Foley, J. A. Monitoring and estimating tropical forest carbon stocks: making REDD a reality. Environ. Res. Lett. 2, 045023 (2007)

7. Somorin, O. et al. The Congo Basin forests in a changing climate: policy discourses on adaptation and mitigation (REDD +). Global Environ. Change 22, 288-298 (2012)

8. Saatchi, S. S. et al. Benchmark map of forest carbon stocks in tropical regions across three continents. Proc. Natl Acad. Sci. USA 108, 9899-9904 (2011).

9. Baccini, A. et al. Estimated carbon dioxide emissions from tropical deforestation improved by carbon-density maps. Nat. Clim. Change 2, 182-185 (2012).

10. Verbeeck, H., Boeckx, P. \& Steppe, K. Tropical forests: include Congo Basin. Nature 479, 179 (2011)

11. Lewis, S. L. et al. Increasing carbon storage in intact African tropical forests. Nature 457, 1003-1006 (2009).

12. Brown, S., Gillespie, A. \& Lugo, A. Biomass estimation methods for tropical forests with applications to forest inventory data. Forest Sci. 35, 881-902 (1989).

13. Chave, J. et al. Tree allometry and improved estimation of carbon stocks and balance in tropical forests. Oecologia 145, 87-99 (2005).

14. Feldpausch, T. R. et al. Tree height integrated into pantropical forest biomass estimates. Biogeosciences 9, 3381-3403 (2012).

15. Henry, M. et al. Wood density, phytomass variations within and among trees, and allometric equations in a tropical rainforest of Africa. For. Ecol. Manage. 260, 1375-1388 (2010).

16. Djomo, A. N., Ibrahima, A., Saborowski, J. \& Gravenhorst, G. Allometric equations for biomass estimations in Cameroon and pan moist tropical equations including biomass data from Africa. For. Ecol. Manage. 260, 1873-1885 (2010).

17. Banin, L. et al. What controls tropical forest architecture? Testing environmental, structural and floristic drivers. Global Ecol. Biogeogr. 21, 1179-1190 (2012)

18. Clark, D. B. \& Clark, D. A. Landscape-scale variation in forest structure and biomass in a tropical rain forest. For. Ecol. Manage. 137, 185-198 (2000).

19. Malhi, Y. et al. The regional variation of aboveground live biomass in old-growth Amazonian forests. Glob. Change Biol. 12, 1107-1138 (2006).

20. Saatchi, S. S., Houghton, R. a., Dos Santos Alvalá, R. C., Soares, J. V. \& Yu, Y. Distribution of aboveground live biomass in the Amazon basin. Glob. Change Biol. 13, 816-837 (2007).

21. Quesada, C. A. et al. Basin-wide variations in Amazon forest structure and function are mediated by both soils and climate. Biogeosciences 9, 2203-2246 (2012).

22. Makana, J.-R. \& Thomas, S. C. Impacts of selective logging and agricultural clearing on forest structure, floristic composition and diversity, and timber tree regeneration in the Ituri forest, Democratic Republic of Congo. Biodivers. Conserv. 15, 1375-1397 (2006).
23. Harper, K. A. et al. Edge influence on forest structure and composition in fragmented landscapes. Conserv. Biol. 19, 768-782 (2005).

24. Laurance, W. F. Forest-climate interactions in fragmented tropical landscapes. Philos. T. Roy. Soc. B 359, 345-352 (2004).

25. Lloyd, J. \& Farquhar, G. D. Effects of rising temperatures and [CO2] on the physiology of tropical forest trees. Philos. T. Roy. Soc. B 363, 1811-1817 (2008).

26. Oliviera-Filho, A. T., Curi, N., Vilela, E. A. \& Carvalho, D. A. Variation in tree community composition and structure with changes in soil properties within a fragments of semideciduous forest in south-eastern Brazil. Edinb. J. Bot. 58, 139-158 (2001).

27. Galbraith et al. Residence times of woody biomass in tropical forests. Plant Ecol. Diversity 6, 139-157 (2013).

28. Laurance, W. F. et al. Relationship between soils and Amazon forest biomass: a landscape-scale study. For. Ecol. Manage. 118, 127-138 (1999).

29. Batjes, N. H. Mapping soil carbon stocks of Central Africa using SOTER. Geoderma 146, 58-65 (2008).

30. Guo, L. \& Gifford, R. Soil carbon stocks and land use change: a meta analysis. Glob. Change Biol. 8, 345-360 (2002).

31. Ramankutty, N. et al. Challenges to estimating carbon emissions from tropical deforestation. Glob. Change Biol. 13, 51-66 (2007).

32. Ogle, S. M., Breidt, F. J. \& Paustian, K. Agricultural management impacts on soil organic carbon storage under moist and dry climatic conditions of temperate and tropical regions. Biogeochemistry 72, 87-121 (2005).

33. DeFries, R. \& Rosenzweig, C. Toward a whole-landscape approach for sustainable land use in the tropics. Proc. Natl Acad. Sci. USA 107, 19627-19632 (2010).

34. Pelletier, J., Codjia, C. \& Potvin, C. Traditional shifting agriculture: tracking forest carbon stock and biodiversity through time in western Panama. Glob. Change Biol. 18, 3581-3595 (2012).

35. Ernst, C. et al. National forest cover change in Congo Basin: deforestation, reforestation, degradation and regeneration for the years 1990, 2000 and 2005 Glob. Change Biol. 19, 1173-1187 (2012).

36. Ebuy, J., Lokombe, J. \& Ponette, Q. Allometric equation for predicting aboveground biomass of three tree species. J. Trop. For. Sci. 23, 125-132 (2011)

37. Peel, M. C., Finlayson, B. L. \& Mcmahon, T. A. Updated world map of the Köppen-Geiger climate classification. Hydrol. Earth Syst. Sci. Discuss. 4, 439-473 (2007).

38. Gilson, P., Van Wambeke, A. \& Gutzweiler, R. Notice Explicative de la Carte des Sols et de la Végétation, $N^{\circ}$ 6: Yangambi, planchette 2: Yangambi (INEAC, 1956).

39. Van Ranst, E., Baert, G., Ngongo, M. \& Mafuka, P. Carte pédologique de Yangambi, planchette 2: Yangambi, échelle 1:50.000. Published by UGent, Hogent, UNILU, UNIKIN. ISBN: 9789491114069 (2010).

40. Verhegghen, A., Mayaux, P., de Wasseige, C. \& Defourny, P. Mapping Congo Basin vegetation types from $300 \mathrm{~m}$ and $1 \mathrm{~km}$ multi-sensor time series for carbon stocks and forest areas estimation. Biogeosciences 9, 5061-5079 (2012).

41. Picard, N., Magnussen, S., Banak, L. N., Namkosserena, S. \& Yalibanda, Y. Permanent sample plots for natural tropical forests: a rationale with special emphasis on Central Africa. Environ. Monit. Assess. 164, 279-295 (2010).

42. Phillips, O. L., Baker, T. R., Brienen, R. \& Feldpausch, T. R. Field manual for plot establishment and remeasurement, available at http:// www.geog.leeds.ac.uk/projects/rainfor/(last access: November 2012) (2010).

43. Pansu, M. \& Gautheyrou, J. Handbook of Soil Analysis: Mineralogical, Organic and Inorganic Methods. p. 993 (Springer, 2006).

44. Peh, K. S.-H., Sonké, B., Lloyd, J., Quesada, C. A. \& Lewis, S. L. Soil does not explain monodominance in a Central African tropical forest. PLOS One 6, e16996 (2011).

45. Hart, T. B., Hart, J. A. \& Murphy, P. G. Monodominant and species-rich forests of the humid tropics: causes for their co-occurrence. Am. Nat. 133, 613-633 (1989).

46. Lewis, S. et al. Aboveground biomass and structure of 260 African tropical forests. Philos. Trans. Roy. Soc. Lond., B, Biol. Soc. 368, 20120295 (2013).

47. Peh, K. S.-H. et al. Investigating diversity dependence of tropical forest litter decomposition: experiments and observations from Central Africa. J. Veg. Sci. 23, 223-235 (2012)

48. Makana, J.-R. et al. Ituri Forest Dynamics Plots, Democratic Republic of Congo. in Tropical Forest Diversity and Dynamism: Findings from a Large-Scale Plot Network (eds Losos, E. \& Leigh, Jr E. G.) 492-505 (University of Chicago Press, 2004).

49. Conway, D. A comparison of Soil Parameters in Monodominant and Mixed Forests in the Ituri Forest Reserves, Zaire. Tropical Environmental Science Honours Project (University of Aberdeen, 1992).

50. Hijmans, R. J., Cameron, S. E., Parra, J. L., Jones, P. G. \& Jarvis, A. Very high resolution interpolated climate surfaces for global land areas. Int. J. Climatol. 25, 1965-1978 (2005). 


\section{Acknowledgements}

This research is part of the COBIMFO project (Congo Basin integrated monitoring for forest carbon mitigation and biodiversity; contract no. SD/AR/01A) and was funded by the Belgian Science Policy Office (Belspo). The fieldwork was possible due to logistic support from WWF and Institut National pour l'Etude et la Recherche Agronomiques YGB. We thank the anonymous reviewers for their valuable comments.

\section{Author contributions}

H.V., P.B. and D.H. developed the project. Y.K. and P.D. undertook site selection using remote sensing. E.K., T.D.H., A.K. and B.T. collected data. G.B. provided soil texture analysis. E.K. and T.D.H. analysed the data. E.K., K.H., H.V., P.B., H.B. and K.S.

interpreted the results and implications. H.V., P.B., H.B., K.S. and J.B. supervised the research. E.K. wrote the paper. All authors commented on the manuscript during the final stages.

\section{Additional information}

Supplementary Information accompanies this paper at http://www.nature.com/ naturecommunications

Competing financial interests: The authors declare no competing financial interests.

Reprints and permission information is available online at http://npg.nature.com/ reprintsandpermissions/

How to cite this article: Kearsley, E. et al. Conventional tree height-diameter relationships significantly overestimate aboveground carbon stocks in the Central Congo Basin. Nat. Commun. 4:2269 doi: 10.1038/ncomms3269 (2013). 